\title{
Structure and Morphology Changes of Zinc Oxide Nanoparticles
}

Luis Hermida Montero ${ }^{1}$, Francisco Paraguay-Delgado ${ }^{2}$ and Nicolaza Pariona Mendoza ${ }^{3}$

${ }^{1}$ Centro de Investigación en Materiales Avanzados S.C. (CIMAV), Chihuahua, Mexico, ${ }^{2}$ Centro de Investigación en Materiales Avanzados, United States, ${ }^{3}$ Instituto de Ecología A.C. (INECOL), United States

Zinc oxide nanoparticles ( $\mathrm{ZnO}-\mathrm{NPs}$ and $\mathrm{ZnO} 2-\mathrm{NPs}$ ) have a great potential for environmental applications due to its good antimicrobial and photocatalytic activity, with low toxicity and low cost [1]. Property optimization of these materials are of interest and can be done by modifying size, shape or by creating crystal defects such as oxygen vacancies [2] and microtensions. In this work particle size and shape of synthesized ZnO-NPs and ZnO2-NPs were studied by TEM and SAED.

ZnO-NPs were synthesized by a hydrothermal method. $1.09 \mathrm{~g}$ of zinc acetate was dissolved in $15 \mathrm{ml}$ of distilled water, then $0.84 \mathrm{~g}$ of $\mathrm{NaOH}$ was added to the solution getting white precipitate. Afterwards, 15 $\mathrm{ml}$ of ethanol was added by slow dripping while stirring. The suspensions were transferred to a Teflon vial and treated at $180^{\circ} \mathrm{C}$ for $18 \mathrm{~h}$. To create oxygen vacancies $224 \mathrm{mg}$ of synthesized ZnO-NPs was dispersed at $150 \mathrm{ml}$ water, then added $150 \mathrm{ml}$ of NaBH4 at $0.04 \mathrm{M}$ aqueous solution and stirred in N2 environment at room temperature for $24 \mathrm{~h}$. Synthesized $\mathrm{ZnO}-\mathrm{NPs}$ were labeled as $\mathrm{ZnO}-\mathrm{H}$ and those treated with $\mathrm{NaBH} 4$ were labeled as $\mathrm{ZnO}-\mathrm{Vo}$. $\mathrm{ZnO} 2-\mathrm{NPs}$ were synthesized by $80 \mathrm{ml}$ of an aqueous solution of zinc sulphate $(75 \mathrm{mM})$ with $40 \mathrm{ml}$ of an aqueous solution of $\mathrm{NaBH} 4(0.79 \mathrm{M})$. Temperatures were maintained at room temperature and $60^{\circ} \mathrm{C}$ for two different synthesis. Afterwards $24 \mathrm{ml}$ of $\mathrm{H} 2 \mathrm{O} 2(30 \%)$ was added and left stirring for $15 \mathrm{~min}$. Samples were labeled as $\mathrm{ZnO} 2-\mathrm{A}$ for synthesis at room temperature and $\mathrm{ZnO} 2-60$ for obtained at $60^{\circ} \mathrm{C}$. Particle size and morphology were studied by TEM and SAED.

Fig. 1 shows the effect of NaBH4 treatment on ZnO-NPs. Synthesized particles (Fig. 1 I) are $\mathrm{ZnO}$ nanosheets with a width of 200-400 $\mathrm{nm}$ and a homogenous thickness of $60 \mathrm{~nm}$. When submitted to NaBH4 treatment (Fig. 1 II). The thickness of the ZnO-NPs is slightly reduced and microtensiones start to appear (as signaled with red arrows). In Fig. 2 we can see morphology of ZnO2-NPs for both temperatures. Fig. 2 I shows nanoparticles below $10 \mathrm{~nm}$ that are highly agglomerated. While in Fig. 2 II we can also see particles below $10 \mathrm{~nm}$, with agglomerations size between 50 and $200 \mathrm{~nm}$. SAED patterns (Fig. 2b) show that $\mathrm{ZnO} 2-60$ have a smaller crystal size than $\mathrm{ZnO} 2-\mathrm{A}$. These results show how NaBH4 treatment and temperature variations in synthesis can modify size, morphology and crystal size of $\mathrm{ZnO}$ and $\mathrm{ZnO} 2 \mathrm{NPs}$. 


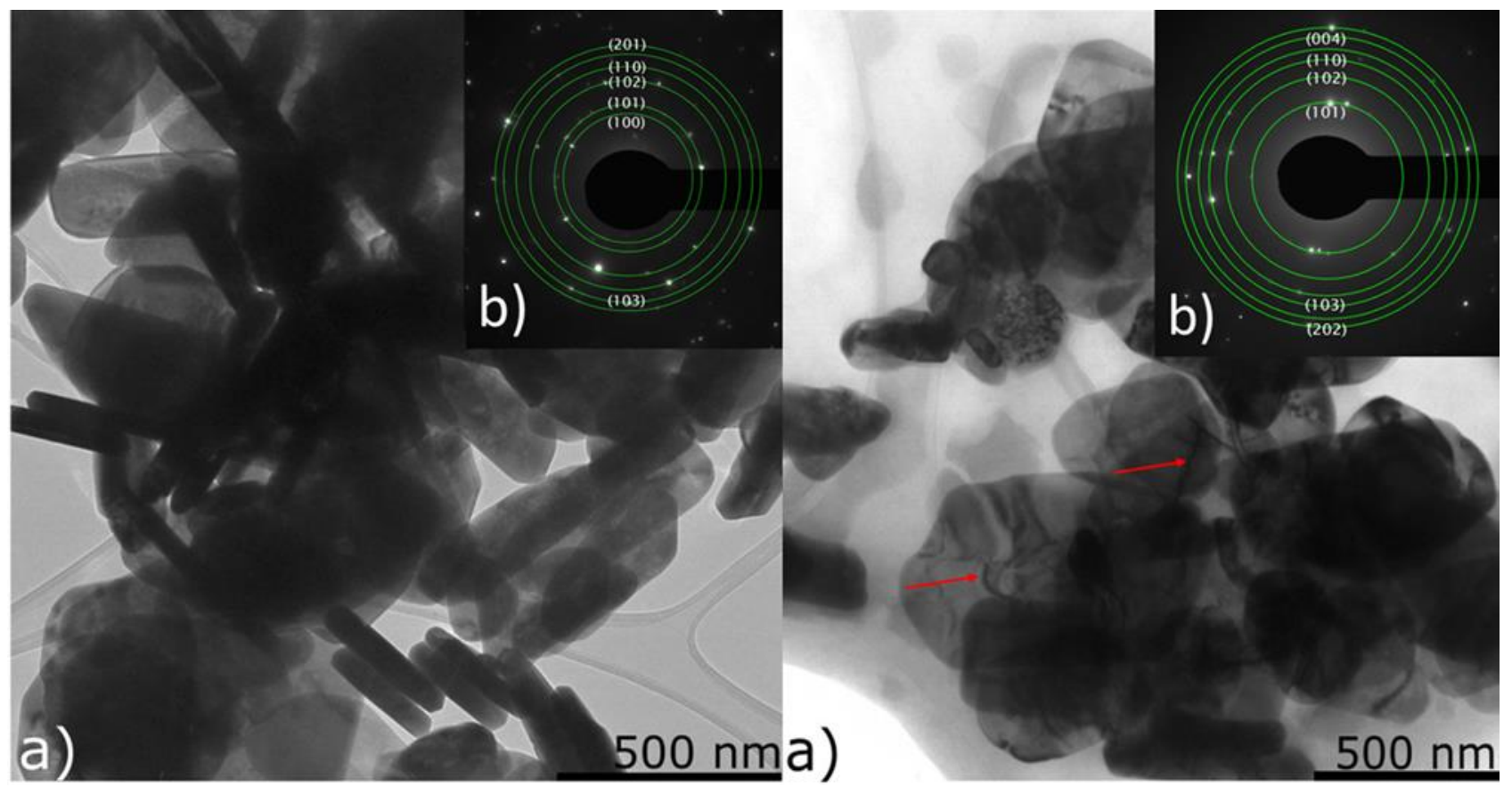

Figure 1. TEM micrographs (a) and SAED patterns (b) of $\mathrm{ZnO}-\mathrm{H}$ (I) and $\mathrm{ZnO}-\mathrm{Vo}$ (II).

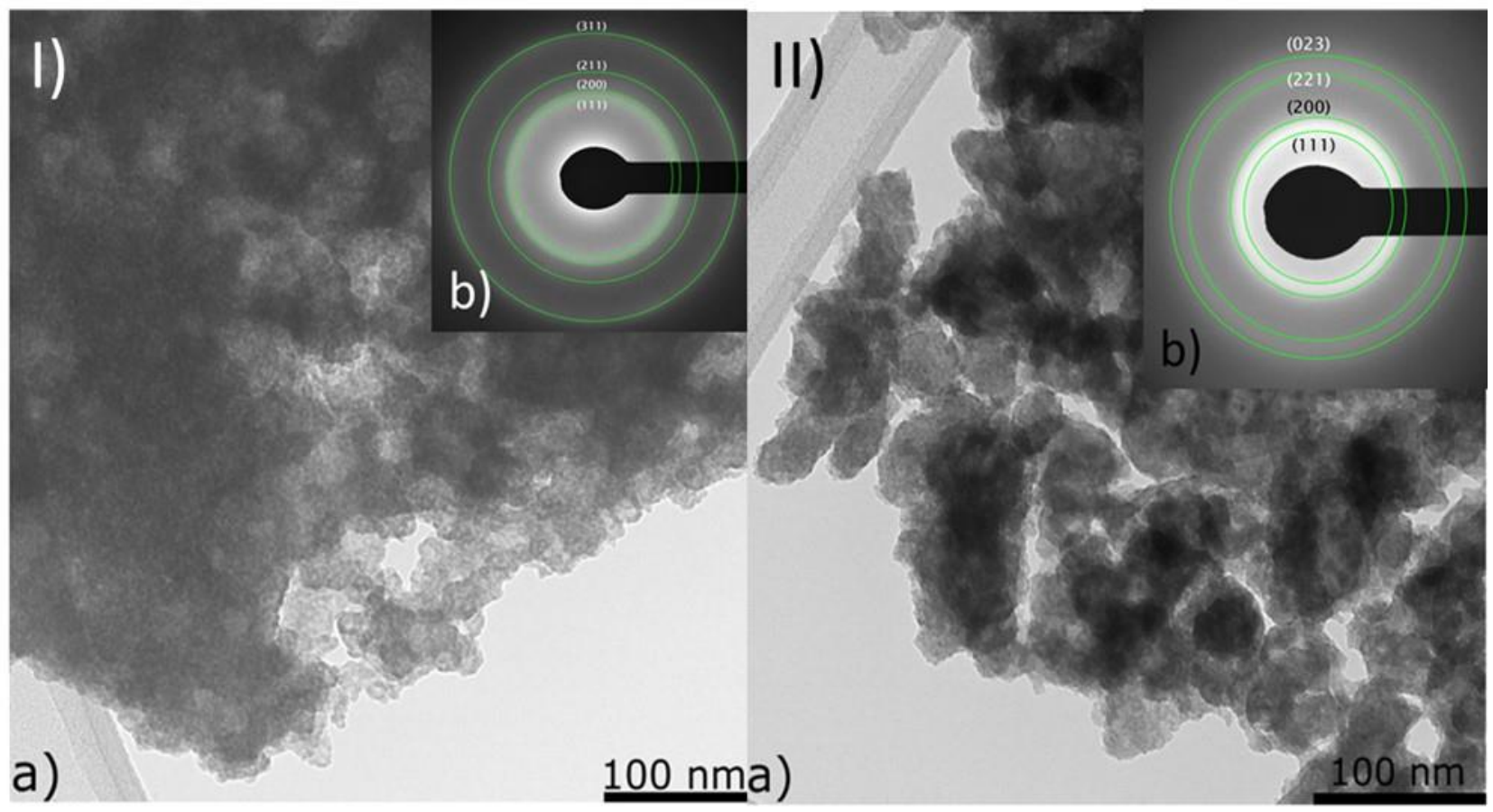

Figure 2. TEM micrographs (a) and SAED patterns (b) of $\mathrm{ZnO} 2-\mathrm{A}$ (I) and $\mathrm{ZnO} 2-60$ (II).

References

[1] W. Huang et al. "The synthesis of ultrasmall ZnO@PEG nanoparticles and its fluorescence properties." J.Sol-Gel Sci. Technol., vol. 74, no.3, p.7, 2015

[2] X. Xu et al., "Antimicrobial mechanism based on $\mathrm{H}_{2} \mathrm{O}_{2}$ generation at oxygen vacancies in $\mathrm{ZnO}$ crystals," Langmuir, vol. 29, no. 18, pp. 5573-5580, 2013. 